\title{
High performance hydroxyapatite ceramics and a triply periodic minimum surface structure fabricated by digital light processing $3 \mathrm{D}$ printing
}

\author{
Yongxia $\mathrm{YAO}^{a, \dagger}$, Wei QIN ${ }^{b, c, \dagger}$, Bohang $\mathrm{XING}^{a}, \mathrm{Na} \mathrm{SHA}^{d, *}$, \\ Ting JIAO ${ }^{b, c, *}$, Zhe $\mathrm{ZHAO}^{a, *}$ \\ ${ }^{a}$ School of Material Science and Engineering, Shanghai Institute of Technology, Shanghai 201418, China \\ ${ }^{b}$ Department of Prosthodontics, Shanghai Ninth People's Hospital, College of Stomatology, \\ School of Medicine, Shanghai Jiao Tong University, Shanghai 200011, China \\ ${ }^{c}$ Shanghai Key Laboratory of Stomatology \& Shanghai Research Institute of Stomatology, National \\ Clinical Research Center for Oral Diseases, Shanghai 200011, China \\ ${ }^{d}$ School of Chemical and Environment Engineering, Shanghai Institute of Technology, Shanghai 201418, China
}

Received: June 3, 2020; Revised: August 23, 2020; Accepted: August 25, 2020

(c) The Author(s) 2020.

\begin{abstract}
High performance hydroxyapatite (HA) ceramics with excellent densification and mechanical properties were successfully fabricated by digital light processing (DLP) three-dimensional (3D) printing technology. It was found that the sintering atmosphere of wet $\mathrm{CO}_{2}$ can dramatically improve the densification process and thus lead to better mechanical properties. HA ceramics with a relative density of $97.12 \%$ and a three-point bending strength of $92.4 \mathrm{MPa}$ can be achieved at a sintering temperature of $1300{ }^{\circ} \mathrm{C}$, which makes a solid foundation for application in bone engineering. Furthermore, a relatively high compressive strength of $4.09 \mathrm{MPa}$ can be also achieved for a DLP-printed p-cell triply periodic minimum surface (TPMS) structure with a porosity of $74 \%$, which meets the requirement of cancellous bone substitutes. A further cell proliferation test demonstrated that the sintering atmosphere of wet $\mathrm{CO}_{2}$ led to improve cell vitality after 7 days of cell culture Moreover, with the possible benefit from the bio-inspired structure, the 3D-printed TPMS structure significantly improved the cell vitality, which is crucial for early osteogenesis and osteointegration.
\end{abstract}

Keywords: hydroxyapatite (HA); 3D printing; sintering atmosphere; mechanical property; bioactivity; digital light processing (DLP)

\section{Introduction}

Hydroxyapatite (HA), $\mathrm{Ca}_{10}\left(\mathrm{PO}_{4}\right)_{6}(\mathrm{OH})_{2}$, is considered

$\dagger$ Yongxia Yao and Wei Qin contributed equally to this work.

* Corresponding authors.

E-mail: Z.Zhao, zhezhao@sit.edu.cn;

T. Jiao, jiao_ting@126.com;

N.Sha, shana@sit.edu.cn to be an ideal ceramic material for bone defect reparation due to its excellent biocompatibility, bioactivity, osteoconductive and the most stable phase, which can promise that bone cells actively adhere, proliferate, and mineralize in the surface of materials [1-3]. Bone tissue engineering is a promising technology of healing bone defects for application in the clinic using functional biomaterial scaffolds. Traditional porous ceramic scaffold fabrication methods, such as sol-gel, 
gas foaming, and freeze-drying, cannot assure the accuracy and desired pores and channels [4]. As known, the porous structure is very important for bio-ceramics, which facilitates cell migration, nutrient delivery, bone ingrowth, or vascularization [5]. However, the structure with high porosity usually shows poor mechanical properties. To develop a perfect porous scaffold of HA, several challenges need to be satisfied, including biocompatibility, high load-bearing capability, and forming of interconnected pores with specific size arrangement [6-9].

In recent years, triply periodic minimum surface (TPMS) structures had gained more attention due to their potential advantages in improved mechanical and biological properties. Many TPMS-like structures can be identified in various nature creatures, such as butterfly wings, nose insects, and crustaceans [10]. TPMS, which exhibits periodicity in three independent directions in three-dimensional (3D) space and has a character of zero mean curvature along the surface, has been regarded as an effective tool for designing scaffolds with gradual and regular porous structure. They were regarded as effective tools for designing scaffolds with gradual and regular porous structures $[11,12]$. Recently, Ali et al. [13] designed eight different bone scaffolds based on TPMS and proved these architectures have a significant impact on permeability. Li et al. [14] successfully prepared the Ti6Al4V scaffold with TPMS of p-cell. With the least surface area, better fluid permeability [14-17] and improved early osteogenesis, osteointegration resulted from the decreased stress shielding effect [14] were achieved with the p-cell TPMS structure. However, there is still no HA bioceramics with such a bio-inspired TPMS structure being studied.

Developing novel processing methods with the capability of realizing complex and strong TPMS structures is of great interest to the next generation scaffold applications. The recent development with ceramic additive manufacturing (AM) technologies opened new routes for achieving the ambitious goals of fabricating complex TPMS structures. AM techniques provide flexible and precise controls over the size and complex shape through a layer-by-layer process [18]. The key bottleneck problem with AM is high-quality printing materials instead of forming shapes. Some investigations on the efforts to develop HA printing materials for various AM methods are reported in the literature. Lasgorceix et al. [19,20] used the stereo- lithographic appearance (SLA) technique to study the feasibility of fabricating HA implants for bone defect reparations but no mechanical properties available. Cox et al. [21] fabricated HA scaffolds through a 3D printing (3DP) method and a rather low compressive strength of $<1 \mathrm{MPa}$ was reported for the scaffolding lattice with about $55 \%$ porosity. By using an improved 3D gel printing (3DGP) method, Shao et al. [22] successfully prepared HA scaffolds composed of rather well-densified ceramic material and the compressive strength can be increased to be $16 \mathrm{MPa}$ when a porosity of $52.26 \%$ was realized for the scaffold. Such a significant improvement in the mechanical property was mainly devoted to the high solid load of $55 \mathrm{vol} \%$ with printing materials, which can reasonably improve the densification of the HA during the sintering. To improve the printing accuracy and efficiency, Liu et al. [23] developed HA ceramic material suitable for the DLP method. The sintering density can reach over $90 \%$ and thus provide the sintered HA a relatively high flexural strength of 41.3 MPa. Based on this strategy, they successfully prepared porous scaffold with a $49.8 \%$ porosity, and a compressive strength of $15.25 \mathrm{MPa}$ was achieved. In general, porous scaffolds prepared by various $\mathrm{AM}$ methods can promise reasonable porosities and pore sizes, but the density and mechanical properties with the printed base materials can be improved. Thus, HA scaffolds with improved mechanical properties at a higher porosity level can be expected if the printing materials can be improved further in the aspect of densification and topologic optimization with porous structures.

In this study, we try to present a different strategy for obtaining well-sintered HA ceramic by DLP 3D printing. Different from the previous studies, both sintering atmospheres and TPMS structures were explored for improving the mechanical and biological properties of the HA scaffold.

\section{Materials and methods}

\section{1 Materials}

In this study, a commercial HA powder (Plasma Biotal P360R, North Derbyshire, UK) with a particle size of $3.97 \mu \mathrm{m}$ was picked as the starting powder for the ultraviolet (UV) curable epoxy resin. The photosensitive resins used are three types of acrylic resins including 2-hydroxyethyl acrylate (HEA), 1,6-hexanediol diacrylate 
(HDDA), and trimethylolpropane triacrylate (TMPTA), which were mentioned in our previous studies [24,25]. The resin materials and dispersant used in this study were obtained from Jiaxing CeramPlus Tech. Ltd., China. The phosphine oxide (TPO, molar mass is $348.4 \mathrm{~g} / \mathrm{mol}$, China) was used in this study as the photoinitiator. The HA powder, photopolymer, photoinitiator, and dispersant were milled with zirconia balls in an attrition milling machine, and the slurry was filtrated through a 100-mesh sieve and then a solid load of 40 vol\% slurry was prepared. We have characterized the particle size of HA powder after dispersion of $0.54 \mu \mathrm{m}$ mentioned in Ref. [26]. The rheological property of the slurry was analyzed to determine the HA ceramic slurry used for DLP printing.

\section{2 Fabrication}

The HA ceramic body was printed by using a top-down DLP printing machine named CeramPlus DLP-50 (Jiaxing CeramPlus Tech. Ltd., China) with a pixel resolution of $50 \mu \mathrm{m}$ which mentioned in our previous study [27]. Firstly, 3D models were created by using the computer design software and the models were exported in stereolithography (STL) format. Then, the STL files were imported into the printing software and the appropriate printing parameters are set. The solidification of the UV resin was realized through a $405 \mathrm{~nm}$ UV-light irradiation [28].

The specific procedure of printing the HA samples in this study was as follows: A $30 \mathrm{~mm} \times 40 \mathrm{~mm} \times 350 \mathrm{~mm}$ solid bar structure model was printed for the study of the sintering and three-point bending strength test. A p-cell porous scaffold structure model (Fig. 1), in which each side has three unit-cells was used for the research of TPMS by structures. After printing, the ethanol was used to clean the extra slurries adhere to the surface of samples and then a secondary UV curing of samples was conducted for $1 \mathrm{~min}$.
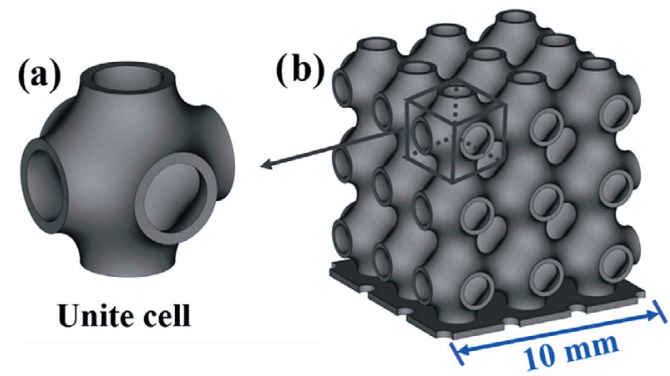

Fig. 1 3D models of (a) the p-cell unite cell and (b) the p-cell scaffold.

\section{3 Sintering procedure}

As shown in the result of TG-DSC (Fig. 2), violent thermal decomposition nearly completed and are stable when the temperature was up to $600{ }^{\circ} \mathrm{C}$. A conventional pressureless sintering method was implemented in the air at a heating rate of $1{ }^{\circ} \mathrm{C} / \mathrm{min}$ up to $600{ }^{\circ} \mathrm{C}$ and held for $1 \mathrm{~h}$ to remove all organics without introducing obvious deformations and cracks. Afterwards, the samples were sintered at five different temperatures of $1100,1150,1200,1250$, and $1300{ }^{\circ} \mathrm{C}$ with a constant heating rate of $5^{\circ} \mathrm{C} \cdot \mathrm{min}^{-1}$, and the dwelling time was also kept as $2 \mathrm{~h}$. Except for these standard sintering procedures, the bar structure samples were also sintered at $1300{ }^{\circ} \mathrm{C}$ in a wet carbon dioxide atmosphere to study the potential influence of the sintering atmospheres.

\section{4 Characteristics and morphology analysis}

The crystal structure and phase purity were characterized by X-ray diffraction (XRD, TD-3500, Tongda, China) with $\mathrm{Cu} \mathrm{K} \alpha$ radiation operating at $35 \mathrm{kV}$ and $25 \mathrm{~mA}$. The XRD was performed over a $2 \theta$ range from $10^{\circ}$ to $80^{\circ}$ at a scanning rate of $10\left(^{\circ}\right) \cdot \mathrm{min}^{-1}$. The microstructural analysis was done using a scanning electron microscope (SEM, Phenom Pro, Phenom World, the Netherlands). The bulk density was measured according to the water immersion method based on the Archimedes principle. The theoretical density of HA was taken as $3.16 \mathrm{~g} \cdot \mathrm{cm}^{-3}$.

\section{5 Mechanical properties}

The mechanical properties of the ceramic bars were evaluated by a three-point bending test and a compression test. The bending tests were performed using a standard testing machine (SUN500, CARDANO AL CAMPVA, Italy) with a loading rate of $0.05 \mathrm{~mm} \cdot \mathrm{min}^{-1}$ according to ISO 14704: 2000. To measure the bending strength $(\sigma)$ of the samples, the equation of three-point bending is as follows:

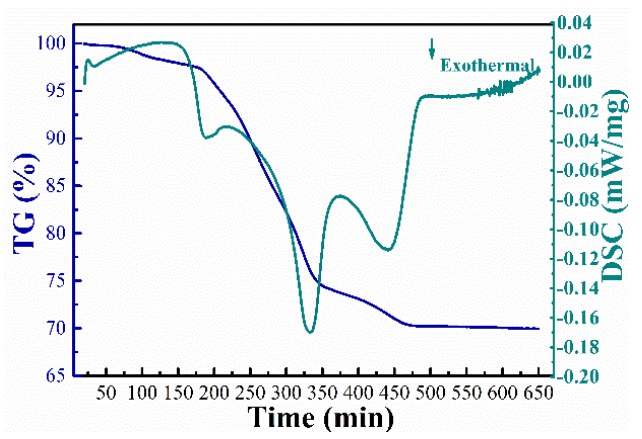

Fig. 2 TG-DSC curves of the HA green ceramic. 


$$
\sigma=\frac{3 F a}{2 b d^{2}}
$$

where $F$ is the load at a given point on the loaddeflection curve, $a$ is the support span, $b$ is the width of the test sample, and $d$ is the depth of the tested bar.

The compression test was conducted by the standard testing machine with a loading rate of $0.2 \mathrm{~mm} \cdot \mathrm{min}^{-1}$ according to JIS R 1608-2003 suitable for porous scaffolds. The equation of compression strength $(\varnothing)$ is as following:

$$
\varnothing=\frac{P}{A}
$$

where $P$ is the critical load and $A$ is the cross-sectional area of scaffolds.

\section{6 Cell viability assessment}

To evaluate the cell compatibility of the HA samples, the cell proliferation was determined by the cell counting kit (CCK)-8 assay. Rat bone marrow mesenchymal stem cells (rBMSCs) were obtained from the femurs and tibias of four-week-old Sprague-Dawley rats (Ninth People's Hospital Animal Center, China) and cultured in high-glucose Dulbecco's modified Eagle medium (DMEM) (HyClone, USA) supplemented with $10 \%$ foetal bovine serum (Gibco, USA) and $100 \mu \mathrm{g} / \mathrm{mL}$ penicillin/streptomycin (HyClone, USA) at $37{ }^{\circ} \mathrm{C}$ in an atmosphere of $5 \% \mathrm{CO}_{2}$. Cells from passages $2-4$ and $80 \%-90 \%$ confluency were used for cell studies. BMSCs were seeded in 24-well plates on discs with no special structures and discs with a p-cell structure whose diameter was $15 \mathrm{~mm}$ and height was $1 \mathrm{~mm}$ in 24-well plates at a density of $1 \times 10^{4}$ cells per well, respectively. After 1-, 3-, and 7-day culture at $37{ }^{\circ} \mathrm{C}$, the CCK-8 solution ( $10 \mu \mathrm{L})$ was added to each well and incubated for $2 \mathrm{~h}$; then the absorbance was measured with the BioTek instrument at $450 \mathrm{~nm}$ (each group has three samples).

\section{7 Statistical analysis}

All data were exhibited as the average \pm standard deviation (SD), and each experiment was repeated at least three times. The statistical comparison was examined by the one-way analysis of variance (ANOVA) followed by a $t$-test. The $P$ values lower than 0.05 were considered statistically significant by using the Origin software.

\section{Results and discussion}

\section{1 Material properties}

The rheological curve of 40 vol\% solid loading HA ceramic suspension is exhibited in Fig. 3. The slurry showed a clear shear thinning behavior at shear rates $<$ $10 \mathrm{~s}^{-1}$ and the viscosity remained rather stable at higher shear rates. The viscosity is $3.7 \mathrm{~Pa} \cdot \mathrm{s}$ at a shear rate of $10 \mathrm{~s}^{-1}$, which is a rather low viscosity compared with the reported ceramic UV resin slurry for DLP. Liu et al. $[23,29]$ reported that the viscosities were $>5 \mathrm{~Pa} \cdot \mathrm{s}$ for a similar solid load. Low viscosity is a guarantee for better printing performance and easier cleaning. The key operating parameters of the HA ceramic 3D DLP printing are light intensity and exposure time to get a reasonably good curing behavior. For the least requirement, the curing depth needs to be at least larger than the printing layer thickness (here we keep using $50 \mu \mathrm{m}$ for all the printing practices). To find a suitable exposure time, a special structure (Fig. 4) was used for this purpose and different exposure time with an increased interval of $400 \mathrm{~ms}$ was added from $0.2 \mathrm{~s}$ as the starting point. It is acknowledged that over-exposed will lead to a reduction of accuracy due to the light scattering and under-exposed conditions may lead to

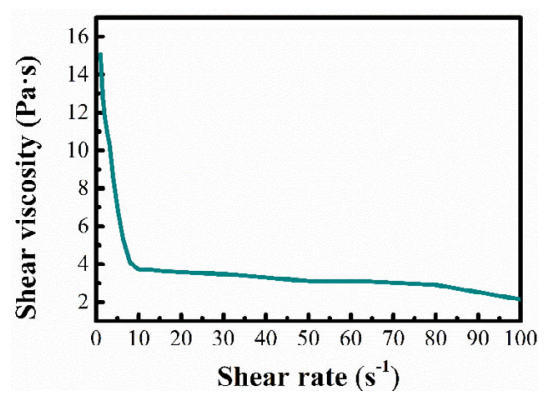

Fig. 3 Viscosity vs. shear rate behavior of the 40 vol\% HA slurry.

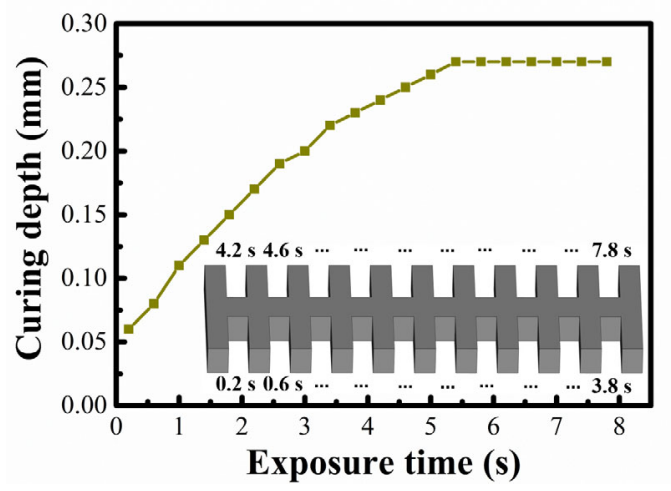

Fig. 4 Curing depth vs. exposure time and the model used to test exposure time. 
the weak bonding between layers, thus resulting in the interface cracks. The results of the experiment exhibited in Fig. 3 proved that an exposure time of $1000 \mathrm{~ms}$ is already enough to promise a curing depth more than twice the designed layer thickness. So, we pick $1000 \mathrm{~ms}$ as the final exposure time. For the build-in layer, instead, we took several printing tests and finally a $5000 \mathrm{~ms}$ of the first layer exposure time can guarantee a good adhesion between the bottom of the printed sample and the platform of the DLP printer. The reason for this longer build-in exposure time is the rather large physical space $(\sim 150 \mu \mathrm{m})$ between the platform surface and the surface of the slurry controlled by the doctor-blade installed with our printing machine.

Densification is one of the most important sintering properties to determine the mechanical properties of HA ceramics and it is the solid foundation for the application of bone engineering. The effect of different sintering temperatures by conventional sintering in the air on the relative density of HA is presented in Fig. 5 . The relative density increased first then decreased with increasing sintering temperature, and the highest relative density of $95.85 \%$ was obtained at $1300{ }^{\circ} \mathrm{C}$. To further investigate the potential benefit by using a wet $\mathrm{CO}_{2}$ atmosphere, $1300{ }^{\circ} \mathrm{C}$ was selected as the sintering temperature. In the wet $\mathrm{CO}_{2}$, the densification of the HA sample can be improved and reached a relative density of $97.12 \%$, but the samples sintered in an ordinary air atmosphere can only reach a relative
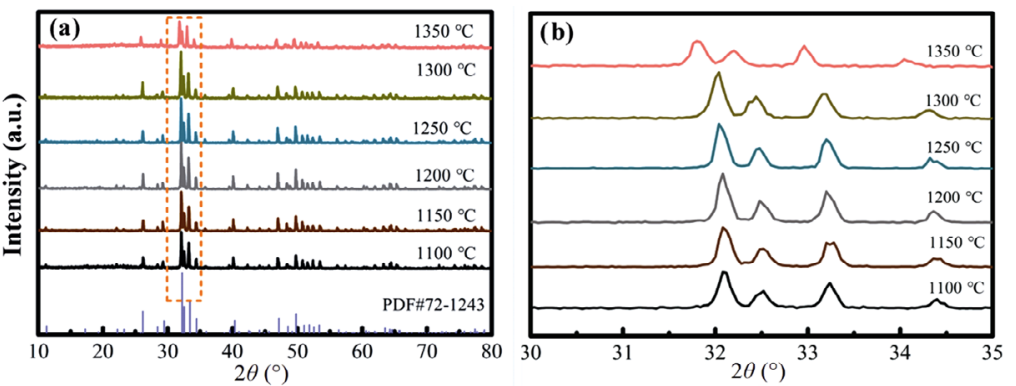

Fig. 6 (a) XRD spectra of the HA samples sintered at different temperatures and (b) partial enlargement ranges from $30^{\circ}$ to $35^{\circ}$.
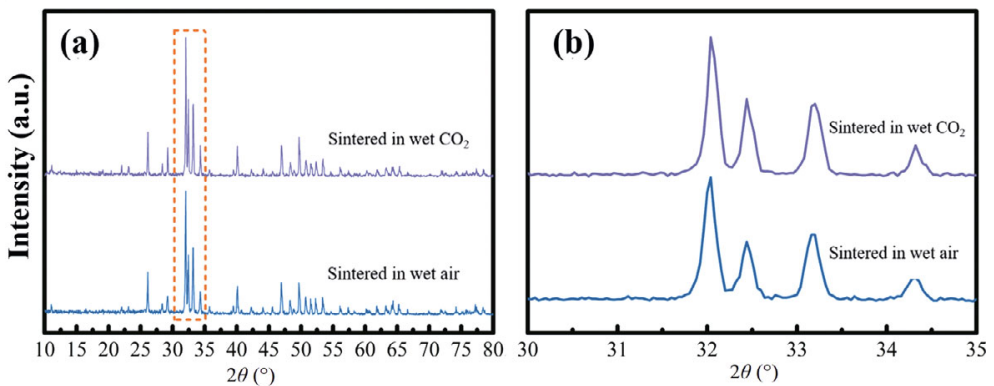

Fig. 7 (a) XRD spectra of the HA samples sintered at $1300{ }^{\circ} \mathrm{C}$ in different sintering atmospheres and (b) partial enlargement ranges from $30^{\circ}$ to $35^{\circ}$. 
and the spectra partial enlargement of the HA samples is given in Fig. 7(b). The diffraction peaks of the HA phase get shaper and full width at half maxima (FWHM) of the HA main peak induced to $0.180^{\circ}$ from $0.191^{\circ}$, which means this sintering atmosphere can effectively improve the crystallinity of HA. It is reported that HA particles may integrate $\mathrm{CO}_{3}^{2-}$ ions in their lattices when the crystals were exposed to air during the synthesis experiment [31]. The sintering atmosphere with wet $\mathrm{CO}_{2}$ can effectively prevent a loss of the carbonate groups from the hydroxyapatite lattice and limited the loss of crystal water during the sintering.

No obvious surface cracks can be observed for HA ceramics sintered in either air or wet $\mathrm{CO}_{2}$. However, more pores can be found in the ceramic sintered in the air (Figs. 8(a) and 8(d)), and clearer traces of the boundaries between layers can be noticed in the HA ceramics sintered in the air (Figs. 8(b) and 8(e)). The reduced structural defects (pores and layer boundaries) achieved by implementing the sintering in wet $\mathrm{CO}_{2}$ were also accompanied by a brighter and more beautiful violet-blue color (Figs. 8(c) and 8(f)). The change of the sintering atmosphere can reduce the pores that caused by the escaped $\mathrm{CO}_{2}$ from dihydroxylation, and promote the densification of ceramics.

\section{2 Mechanical properties}

In order to fabricate qualified bone scaffolds, adequate mechanical properties are vital for the HA porosity structures. As shown in Fig. 10, the bending strength of the HA ceramics sintered in the air was $64.11 \mathrm{MPa}$ and the flexural modulus was $3.44 \mathrm{GPa}$ while the bending strength of the samples sintered in wet $\mathrm{CO}_{2}$ was $92.4 \mathrm{MPa}$ and the flexural modulus was $3.24 \mathrm{GPa}$. The mechanical characterization shows that the samples sintered in wet

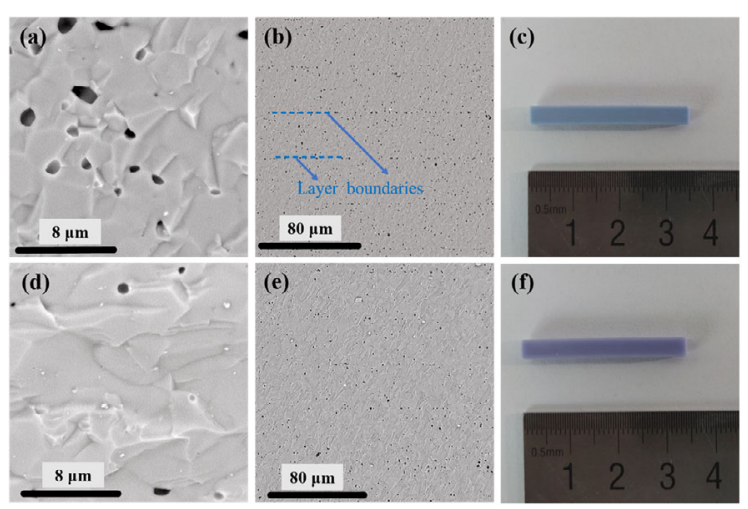

Fig. 8 (a-c) SEM images and optical pictures of the samples sintered at $1300{ }^{\circ} \mathrm{C}$ in the air and (d-f) wet $\mathrm{CO}_{2}$.

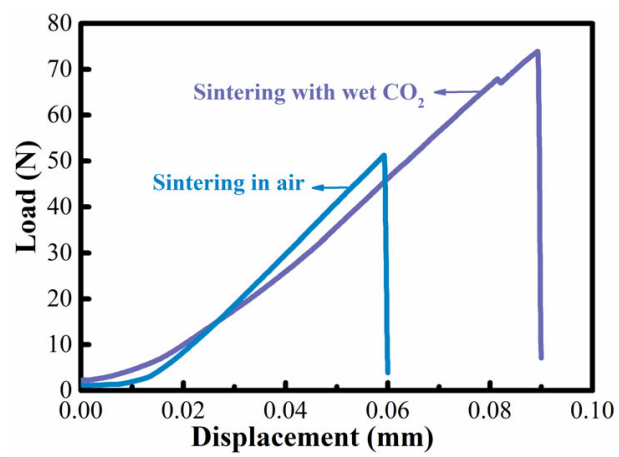

Fig. 9 Load-displacement cure for three-point bending test of HA samples sintered at $1300{ }^{\circ} \mathrm{C}$ with different sintering atmospheres.

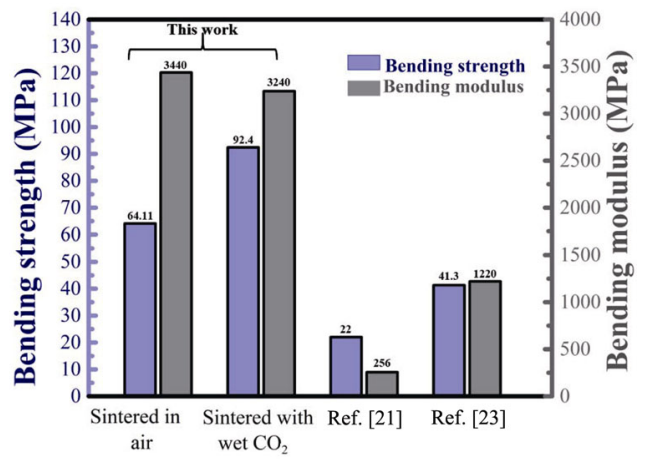

Fig. 10 Comparison of the mechanical properties between HA ceramic materials prepared by stereolithography methods.

$\mathrm{CO}_{2}$ have a better bending strength and significantly higher than the mechanical performance reported by Scalera et al. [32] and Liu et al. [23]. Furthermore, the bending strength was close to the best-reported results of 84.3-101.2 MPa with a relative density of $97.1 \%$ 99\% achieved through careful ceramic powder processing and sintering [33]. The sintering atmosphere of wet $\mathrm{CO}_{2}$ played an effective role in limiting the loss of carbonate groups from the hydroxyapatite lattice, which can decrease the internal pores produced from the escape of $\mathrm{CO}_{2}$ due to the decomposition of $\mathrm{CO}_{3}^{2-}$ and finally improve the mechanical-biological properties [34]. In addition, parts of internal pores caused by dihydroxylation lowered because of the use of wet atmosphere.

The p-cell porous scaffolds sintered in wet $\mathrm{CO}_{2}$ had a high porosity of $74 \%$ and physical drawings of the as-sintered HA scaffold are provided in Fig. 11(a). The compressive strength of the p-cell porous scaffold was about 4.09 MPa showed in Fig. 12, which is close to that of cancellous bones (1.9-7 MPa) in human bodies [35]. Compared to the early studies showed in Table 1 about porous HA ceramic, Feng et al. [29] fabricated a $54 \%$ porosity HA scaffold with only $1.45 \mathrm{MPa}$ compression strength via DLP and Liu et al. [23] 
Table 1 Porosity and compression strength of $\mathrm{HA}$ scaffolds prepared by DLP with different structures in the reported studies

\begin{tabular}{ccc}
\hline Porosity (\%) & Compression strength (MPa) & Ref. \\
\hline 54.5 & 1.45 & {$[29]$} \\
49.8 & 15.25 & {$[23]$} \\
74 & 4.09 & This study \\
\hline
\end{tabular}
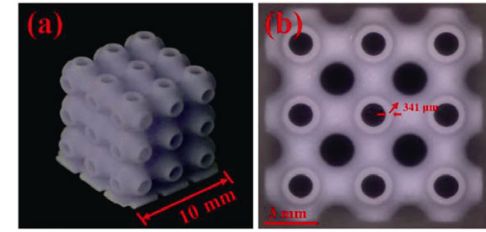

(c)

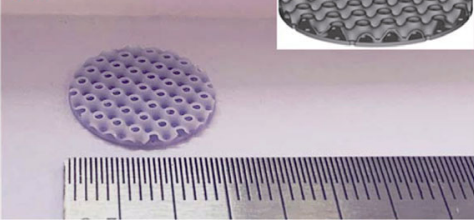

Fig. 11 (a) A photo of the sintered p-cell scaffold; (b) top-view of the p-cell scaffold; (c) photo and 3D model of p-cell plate used for cell viability test.

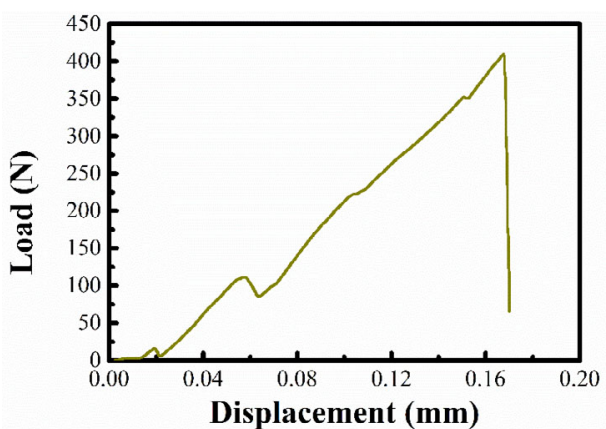

Fig. 12 Load-displacement curve for a typical compression test with the HA p-cell structure.

prepared a relatively better compressive strength of $15.25 \mathrm{MPa}$ with only $49.8 \%$ porosity by DLP, the p-cell porous HA scaffold printed by DLP had a high porosity with a fine compressive strength mainly owing to the same aperture size, desired internal apertures, uniform internal structure, and excellent homogeneity. Figure 12 also shows that such a scaffold does not collapse promptly when the sample under the weight load because a great deal of the same unit cell carrying capacity is uniformly avoided stress concentration.

\section{3 Cell viability in vitro}

MSCs can differentiate into mature cells of multiple mesenchymal tissues including bones, fats, cartilages, and nerves [36]. The rBMSCs were obtained and processed as described in Ref. [37]. The cell viability and adhesion of rBMSCs cultured with two different sintering atmospheres of two kinds of HA plates without any structures and with a p-cell structure in the same size given in Fig.11(c) were assessed.

The optical density (OD) value is consistent with cell proliferation on the sample surface and a higher OD value represents a higher cell vitality. The absorbance produced by metabolically active live cells cultured for 1-, 3-, and 7-day in test samples is shown in Fig. 13. None of the samples showed any significant toxicity towards rBMSC cells after cultured. The OD value of cells was increased with the incubation time, indicating that the surface of the HA samples provides a suitable environment for cell growth and proliferation. The OD amplification of the $\mathrm{HA}$ pattern sintered in wet $\mathrm{CO}_{2}$ increased significantly in 7 days and exceeded another sample only sintered in air. Figure 14 shows the fluorescence microscopy analysis of rBMSCs after 3 days of culture on two different sintering atmospheres of HA discs without any structures and the same size discs with a p-cell structure. The results indicated that the p-cell structure promoted more cells adhered to the surface of HA discs more than those without any structures.

The adhesion of cells to the surfaces of strong hydroxyl groups has drawn widespread attention since discovered by Curtis et al. [38]. It has proven that hydroxyl groups are remarkably stimulatory to cell adhesion and proliferation in a subsequent study [39]. The sintering atmosphere with $\mathrm{H}_{2} \mathrm{O}$ and $\mathrm{CO}_{2}$ is likely to restrain the dihydroxylation:

$$
\mathrm{Ca}_{5}\left(\mathrm{PO}_{4}\right)_{3}(\mathrm{OH}) \rightarrow \mathrm{Ca}_{5}\left(\mathrm{PO}_{4}\right)_{3}(\mathrm{OH})_{1-x} \mathrm{O}_{x}+\frac{x}{2} \mathrm{H}_{2} \mathrm{O}
$$

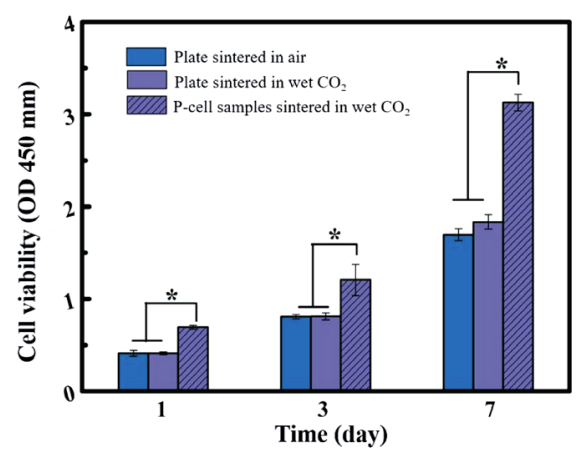

Fig. 13 CCK-8 test results of rBMSCs proliferation of HA flat plates sintered at $1300{ }^{\circ} \mathrm{C}$ in different atmospheres and p-cell samples sintered at $1300{ }^{\circ} \mathrm{C}$ in wet $\mathrm{CO}_{2}$. 
This in vitro experimental study showed the characteristics of material itself had a prominent influence on cell adhesion and proliferation as well as the auxoaction for cell growth and proliferation of samples sintered atmosphere in wet $\mathrm{CO}_{2}$.

Based on the sintering atmosphere with wet $\mathrm{CO}_{2}$, HA plates with p-cell porous structures show better biological activity than that with no special structures which are revealed in Figs. 13 and 14. From the OD values, all HA samples showed good cytocompatibility due to the increase of the cell numbers in all groups with a 7-day culture. The statistical analysis demonstrated that the samples with p-cell structures had a significant difference and higher cell density compared with the the samples without structures. The p-cell structure that has a high porosity and interconnected channels made the samples great transportability for nutrients and oxygen, which led the samples more suitable for cell sustaining viability and proliferation. Hench et al. [40,41] have already proved that inherent characteristics brought by the design and fabrication of 3D printing, including pore characteristics, surface properties, and mass transport abilities had noteworthy influences on cell attachment, proliferation, and differentiation on different scaffold structures. We will further explore whether HA with p-cell structures can promote osteogenic differentiation of MSCs for a better application in bone tissue engineering.
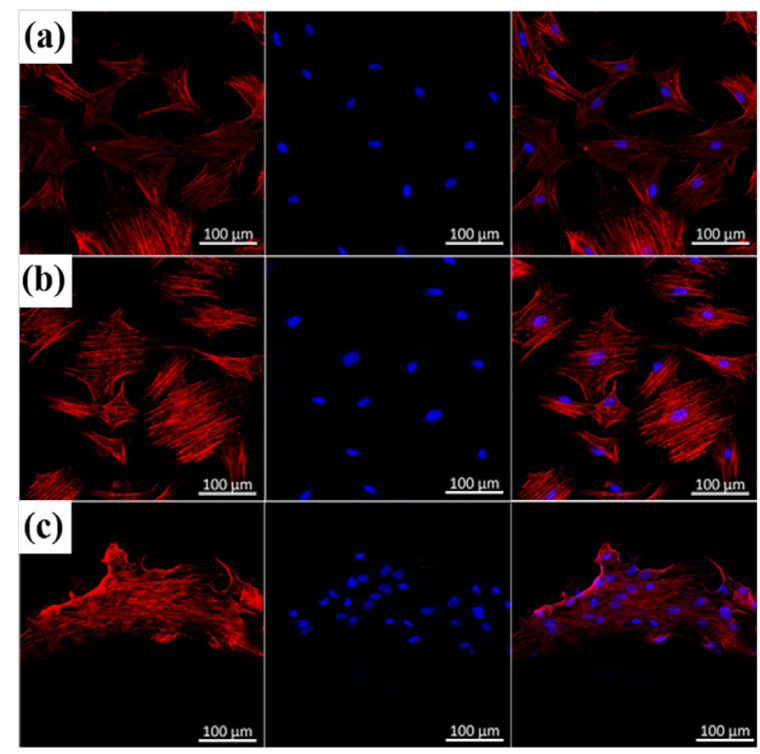

Fig. 14 Fluorescence images $(200 \times)$ rBMSCs stained with DAPI and rhodamine-phalloidin on HA plates sintered at $1300{ }^{\circ} \mathrm{C}$ in different atmospheres and p-cell samples sintered at $1300{ }^{\circ} \mathrm{C}$ in wet $\mathrm{CO}_{2}$ after 3 days of culture: (a) plates sintered in air, (b) plates sintered in wet $\mathrm{CO}_{2}$, and (c) p-cell samples sintered in wet $\mathrm{CO}_{2}$.

\section{Conclusions}

In this study, a HA ceramic slurry with 40 vol\% solid loading was successfully used to print bending test bars and p-cell TPMS structures by the DLP 3D printing method. The conclusions are as follows:

1) Sintering the atmosphere of wet $\mathrm{CO}_{2}$ can dramatically improve the densification process and thus lead to better mechanical properties of HA ceramics. A dense HA ceramic with a density of $97.12 \%$ can be obtained at a sintering temperature of $1300{ }^{\circ} \mathrm{C}$ in a wet $\mathrm{CO}_{2}$ atmosphere. The bending strength and flexural modulus of HA samples were 92.4 MPa and 3.24 GPa, respectively, which were close to the best results (84.3-101.2 MPa) from the conventional ceramic powder processing and sintering. High densification and excellent mechanical properties make a solid foundation for the application of bone engineering.

2) The sintering atmosphere of wet $\mathrm{CO}_{2}$ also produces a positive influence on biological activity. The atmosphere could restrain dihydroxylation and boost cell growth, adhesion, and proliferation.

3) The DLP printing can fabricate complex p-cell structures HA ceramic with high repeatability and accuracy. A relatively high compressive strength of 4.09 $\mathrm{MPa}$ can be also achieved for a DLP-printed p-cell TPMS structure with a porosity of $74 \%$ after sintering in wet $\mathrm{CO}_{2}$ at $1300{ }^{\circ} \mathrm{C}$. Compared with the HA plate sample, the cell viability of the HA sample with p-cell structure was significantly improved $(70.45 \%)$. This was tentatively attributed to the curved surfaces and a large number of internal pores, all these structure characteristics can facilitate the cell attachment and prefoliation with this bio-inspired structure.

Finally, high performance and bio-inspired TMPS structure with a complex shape and flexible feature design can be realized by the novel DLP 3D printing method. The integration of the production of HA scaffolds and TPMS structures showed great potential for early osteogenesis and osteointegration.

\section{Acknowledgements}

This study was supported by the National Key R\&D Program of China (2017YFB1103500 and 2017YFB1103502).

\section{References}

[1] Wei GB, Ma PX. Structure and properties of nano-hydrox- 
yapatite/polymer composite scaffolds for bone tissue engineering. Biomaterials 2004, 25: 4749-4757.

[2] Lin KF, He S, Song Y, et al. Low-temperature additive manufacturing of biomimic three-dimensional hydroxyapatite/ collagen scaffolds for bone regeneration. ACS Appl Mater Interfaces 2016, 8: 6905-6916.

[3] Nowicki MA, Castro NJ, Plesniak MW, et al. 3D printing of novel osteochondral scaffolds with graded microstructure. Nanotechnology 2016, 27: 414001.

[4] Chen RY, Jia WB, Hei DQ, et al. Toward excellent performance of $\mathrm{Al}_{2} \mathrm{O}_{3}-\mathrm{ZrO}_{2}$ reticulated porous ceramics: New insights based on residual stress. Ceram Int 2018, 44: 21478-21485.

[5] Fu SY, Zhu M, Zhu YF. Organosilicon polymer-derived ceramics: An overview. J Adv Ceram 2019, 8: 457-478.

[6] Hutmacher DW. Scaffolds in tissue engineering bone and cartilage. Biomaterials 2000, 21: 2529-2543.

[7] Rezwan K, Chen QZ, Blaker JJ, et al. Biodegradable and bioactive porous polymer/inorganic composite scaffolds for bone tissue engineering. Biomaterials 2006, 27: 3413-3431.

[8] Bártolo PJ, Chua CK, Almeida HA, et al. Biomanufacturing for tissue engineering: Present and future trends. Virtual Phys Prototyp 2009, 4: 203-216.

[9] Giannitelli SM, Accoto D, Trombetta M, et al. Current trends in the design of scaffolds for computer-aided tissue engineering. Acta Biomater 2014, 10: 580-594.

[10] Kapfer SC, Hyde ST, Mecke K, et al. Minimal surface scaffold designs for tissue engineering. Biomaterials 2011, 32: 6875-6882.

[11] Yoo DJ. Porous scaffold design using the distance field and triply periodic minimal surface models. Biomaterials 2011, 32: 7741-7754.

[12] Shi JP, Yang JQ, Zhu LY, et al. A porous scaffold design method for bone tissue engineering using triply periodic minimal surfaces. IEEE Access 2018, 6: 1015-1022.

[13] Ali D, Ozalp M, Blanquer SBG, et al. Permeability and fluid flow-induced wall shear stress in bone scaffolds with TPMS and lattice architectures: A CFD analysis. Eur $J$ Mech-B 2020, 79: 376-385.

[14] Li L, Shi JP, Zhang KJ, et al. Early osteointegration evaluation of porous $\mathrm{Ti}_{6} \mathrm{Al}_{4} \mathrm{~V}$ scaffolds designed based on triply periodic minimal surface models. J Orthop Transl 2019, 19: 94-105.

[15] Jung Y, Chu KT, Torquato S. A variational level set approach for surface area minimization of triply-periodic surfaces. J Comput Phys 2007, 223: 711-730.

[16] Jung Y, Torquato S. Fluid permeabilities of triply periodic minimal surfaces. Phys Rev E 2005, 72: 056319.

[17] Guest JK, Prévost JH. Optimizing multifunctional materials: Design of microstructures for maximized stiffness and fluid permeability. Int J Solids Struct 2006, 43: 7028-7047.

[18] Bhushan B, Caspers M. An overview of additive manufacturing (3D printing) for microfabrication. Microsyst Technol 2017, 23: 1117-1124.
[19] Lasgorceix M, Champion E, Chartier T. Shaping by microstereolithography and sintering of macro-microporous silicon substituted hydroxyapatite. J Eur Ceram Soc 2016, 36: 1091-1101.

[20] Brie J, Chartier T, Chaput C, et al. A new custom made bioceramic implant for the repair of large and complex craniofacial bone defects. J Cranio-Maxillofac Surg 2013, 41: 403-407.

[21] Cox SC, Thornby JA, Gibbons GJ, et al. 3D printing of porous hydroxyapatite scaffolds intended for use in bone tissue engineering applications. Mater Sci Eng: C 2015, 47: 237-247.

[22] Shao HP, He JZ, Lin T, et al. 3D gel-printing of hydroxyapatite scaffold for bone tissue engineering. Ceram Int 2019, 45: 1163-1170.

[23] Liu ZB, Liang HX, Shi TS, et al. Additive manufacturing of hydroxyapatite bone scaffolds via digital light processing and in vitro compatibility. Ceram Int 2019, 45: 11079-11086.

[24] Zhang S, Sha N, Zhao Z. Surface modification of $\alpha-\mathrm{Al}_{2} \mathrm{O}_{3}$ with dicarboxylic acids for the preparation of UV-curable ceramic suspensions. J Eur Ceram Soc 2017, 37: 1607-1616.

[25] Li KH, Zhao Z. The effect of the surfactants on the formulation of UV-curable SLA alumina suspension. Ceram Int 2017, 43: 4761-4767.

[26] Yao YX, Sha N, Zhao Z. Highly concentrated hydroxyapatite suspension for DLP printing. IOP Conf Ser: Mater Sci Eng 2019, 678: 012016.

[27] Xing BH, Yao YX, Meng X, et al. Self-supported yttria-stabilized zirconia ripple-shaped electrolyte for solid oxide fuel cells application by digital light processing three-dimension printing. Scripta Mater 2020, 181: 62-65.

[28] Stansbury JW, Idacavage MJ. 3D printing with polymers: Challenges among expanding options and opportunities. Dent Mater 2016, 32: 54-64.

[29] Feng CW, Zhang KQ, He RJ, et al. Additive manufacturing of hydroxyapatite bioceramic scaffolds: Dispersion, digital light processing, sintering, mechanical properties, and biocompatibility. $J$ Adv Ceram 2020, 9: 360-373.

[30] Bose S, Saha SK. Synthesis of hydroxyapatite nanopowders via sucrose-templated Sol-gel method. J Am Ceram Soc 2003, 86: 1055-1057.

[31] Cheng ZH, Yasukawa A, Kandori K, et al. FTIR Study on incorporation of $\mathrm{CO}_{2}$ into calcium hydroxyapatite. Faraday Trans 1998, 94: 1501-1505.

[32] Scalera F, Esposito Corcione C, Montagna F, et al. Development and characterization of UV curable epoxy/ hydroxyapatite suspensions for stereolithography applied to bone tissue engineering. Ceram Int 2014, 40: 15455-15462.

[33] Rapacz-Kmita A, Ślósarczyk A, Paszkiewicz Z. Mechanical properties of $\mathrm{HAp}-\mathrm{ZrO}_{2}$ composites. J Eur Ceram Soc 2006, 26: $1481-1488$.

[34] Gibson IR, Bonfield W. Novel synthesis and characterization of an AB-type carbonate-substituted hydroxyapatite. $J$ Biomed Mater Res 2002, 59: 697-708.

[35] Zhao HX, Liang WH. A novel comby scaffold with improved 
mechanical strength for bone tissue engineering. Mater Lett 2017, 194: 220-223.

[36] Herzog EL, Chai L, Krause DS. Plasticity of marrowderived stem cells. Blood 2003, 102: 3483-3493.

[37] González-Vázquez A, Planell JA, Engel E. Extracellular calcium and CaSR drive osteoinduction in mesenchymal stromal cells. Acta Biomater 2014, 10: 2824-2833.

[38] Curtis AS, Forrester JV, McInnes C, et al. Adhesion of cells to polystyrene surfaces. J Cell Biol 1983, 97: 1500-1506.

[39] Liu XM, Lim JY, Donahue HJ, et al. Influence of substratum surface chemistry/energy and topography on the human fetal osteoblastic cell line hFOB 1.19: Phenotypic and genotypic responses observed in vitro. Biomaterials 2007, 28: 4535-4550.

[40] Hench LL. Bioceramics: from concept to clinic. $J \mathrm{Am}$ Ceram Soc 1991, 74: 1487-1510.

[41] Van Bael S, Chai YC, Truscello S, et al. The effect of pore geometry on the in vitro biological behavior of human periosteum-derived cells seeded on selective laser-melted $\mathrm{Ti}_{6} \mathrm{Al}_{4} \mathrm{~V}$ bone scaffolds. Acta Biomater 2012, 8: 2824-2834.

Open Access This article is licensed under a Creative Commons Attribution 4.0 International License, which permits use, sharing, adaptation, distribution and reproduction in any medium or format, as long as you give appropriate credit to the original author(s) and the source, provide a link to the Creative Commons licence, and indicate if changes were made.

The images or other third party material in this article are included in the article's Creative Commons licence, unless indicated otherwise in a credit line to the material. If material is not included in the article's Creative Commons licence and your intended use is not permitted by statutory regulation or exceeds the permitted use, you will need to obtain permission directly from the copyright holder.

To view a copy of this licence, visit http://creativecommons. org/licenses/by/4.0/. 